\title{
Heavy Metals Accumulation in Trees Grown in Urban and Rural Areas
}

\author{
Shrrog Hammed Hlail \\ Department of Biology, College of Education for Pure Science, University of Thi-Qar, Nasiriyah, Iraq \\ Email: shrooq_hammed@yahoo.com
}

How to cite this paper: Hlail, S. H. (2019).

Heavy Metals Accumulation in Trees Grown in Urban and Rural Areas. Journal of Geoscience and Environment Protection, 7, 69-75.

https://doi.org/10.4236/gep.2019.78005

Received: June 2, 2019

Accepted: August 9, 2019

Published: August 12, 2019

Copyright $\odot 2019$ by author(s) and Scientific Research Publishing Inc. This work is licensed under the Creative Commons Attribution International License (CC BY 4.0).

http://creativecommons.org/licenses/by/4.0/

(c) (i) Open Access

\begin{abstract}
Since heavy metals are the big concerns for the public health today. Metals play a vital role as structural and functional components of proteins and enzymes in cell. The most important pathway of metals to transport into human is from soil to plant to human, so this study was carried out to measure the contents of heavy metals concentrations in plants leaves from their natural habitats of urban and rural area in Nasiriyah city, Iraq. The study was conducted to investigate the heavy metals content of four plant species of Eucalyptus, Olea, Zizphus and Conocarpus from urban (Nasiriyah city) and rural area (farms north of Nasiriyah). The concentration of heavy metals was tested, including the zinc, copper and lead. Heavy metals were detected using an atomic absorption spectrometer. The results showed that the highest concentration of heavy metals in Olea leaves and Eucalyptus leaves were found from the urban areas. $\mathrm{Zn}$ was the most dominant metal whereas $\mathrm{Pb}$ had the lowest concentration for all urban and rural area. Among the Eucalyptus, Olea, Zizphus and Conocarpus studied, showed higher heavy metals concentration $(\mathrm{Zn}, \mathrm{Cu}$ and $\mathrm{Pb})$ than rural area. The results indicated that the Zizphus and Conocarpus leaves of urban and rural area had the lowest heavy metals content compared with Eucalyptus and Olea. The results suggested that Eucalyptus and Olea leaves are good sources to treat the pollution of heavy metals. Our study provides a detailed examination of habitat location and plant species effects on potential of heavy metals in trees.
\end{abstract}

\section{Keywords}

Heavy Metals, Urban and Rural Area, Eucalyptus, Olea, Zizphus, Conocarpus

\section{Introduction}

Pollution is the spread of pollutants in natural environments that negatively af- 
fect the components of the ecosystem soil, water, plants and human health (Lone et al., 2008; Abdelhafez et al., 2014). Studies indicate that there are some factors that control the severity of the pollutant: its chemical nature, concentration and stability (Miller, 2007). Heavy metals have been widely spread as a result of human activities, leading to an excess accumulation that exceeds the permissible limits causing serious environmental disaster (Huseyinova et al., 2009). Heavy metals are relatively difficult to define, in spite of their shared physical properties. Therefore, the definition of heavy metals tends to be based on the toxicity of the compounds. Furthermore, they can be further classified based on their weight, hence why they are considered to be "heavy"; all heavy metals weigh over $5 \mathrm{~g} / \mathrm{cm}^{3}$. Examples include lead $(\mathrm{Pb})$, zinc $(\mathrm{Zn})$, mercury $(\mathrm{Hg})$, cadmium $(\mathrm{Cd})$, arsenic $(\mathrm{As})$, chromium $(\mathrm{Cr})$, copper $(\mathrm{Cu})$ silver $(\mathrm{Ag})$, iron $(\mathrm{Fe})$, and the platinum group (Hawkes, 1997; Hutton \& Symon, 1986). Taking in especially high concentrations of such heavy metals $(\mathrm{Pb}, \mathrm{Cd}, \mathrm{Hg}$ and $\mathrm{As})$ can be toxic to the plants, thereby resulting in heavy metal poisoning although they continue to be toxic for humans, even when present at very low concentrations (Jansen et al., 1994). There are many properties of heavy metals that are unique to their classification. Plants used for treatment in urban areas with congested traffic have several benefits in addition to their aesthetic value and soil conservation, windbreakers, providing for humans and animals and use in medicine and reduce air pollution (Cetin, 2016). Plants are always used as biomonitors in the accumulation of heavy metals. Plants living in polluted areas show symptoms of accumulation of heavy metals in different parts of them (Kulshreshtha et al., 2010). Some plants have the ability to absorb heavy elements in different plant tissues more than others (Aksoy et al., 2012). Thus, the selection of plants is very important in pollution treatment programs in polluted areas (Malakootian et al., 2009). The aim of this study is to determine heavy metals concentrations plants leaves (Eucalyptus, Olea, Zizphus and Conocarpus) from urban and rural area in Nasiriyah city.

\section{Materials and Methods}

\subsection{Study Area}

Leaves of four different species of plants (Eucalyptus, Olea, Zizphus and Conocarpus) samples were collected from two sampling stations which were: 1) Nasiriyah city, 2) Farms north of Nasiriyah. For each sampling location, three samples replicate were taken $(n=3)$.

\subsection{Plant Samples}

For plant parts, leaves were collected at the same sites where the plant samples were taken. The leaves were carefully hand-picked from the trees at young stage (free diseases). All samples were saved in box during transporting back to the laboratory at the Department of Biology, University of Thi-Qar. plant samples were washed with tap water to remove soil particles twice with distilled water 
and deionized water. The plant leaves of Eucalyptus, Olea, Zizphus and Conocarpus were cut into small pieces, and then oven dried at $60^{\circ} \mathrm{C}$ for $48 \mathrm{~h}$ (AOAC, 1984).

\subsection{Samples Digestion}

Extraction of heavy metals from Eucalyptus, Olea, Zizphus and Conocarpus leaves were done by wet digestion according to the Monni et al. (2000). Dried samples were weighed in a conical flask with $\mathrm{HNO}_{3}: \mathrm{HCIO}_{4}(2: 1)$ for 3 - 4 hours on a sand bath at a temperature of $100^{\circ} \mathrm{C}$ until all brown fumes had changed to white. Digested samples were filtered with a $0.45 \mu \mathrm{m}$ pore size cellulose nitrate membrane filter paper and the volume was made up to $50 \mathrm{ml}$ with deionized water. Heavy metals concentrations were determined by atomic absorption spectrometer.

\subsection{Statistical Analysis}

All the analyses were conducted in triplicates for each location. The heavy metals for the leaves extracts were evaluated with the two-way ANOVA and L.S.D triplicates range test using SPSS software (SPSS ver.23). P values less than 0.05 were considered to be statistically significant. Values were expressed in means \pm SD (Bryman \& Cramer, 2012).

\section{Results and Discussion}

\subsection{The Zinc Content of Eucalyptus, Olea, Zizphus and Conocarpus Leaves}

The result showed that the $\mathrm{Zn}$ accumulation in rural area were less than urban area in all plant species. Regarding the $\mathrm{Zn}$ content in trees, accumulation of these metals by leaves also increased respectively in urban area compare with remote area. The effects of species and growing location (rural and urban areas) in $\mathrm{Zn}$ content is shown in Table 1. Significant differences $(p<0.05)$ in $\mathrm{Zn}$ concentration in leaves of Eucalyptus, Olea, Zizphus and Conocarpus were found among the different growing location. Olea leaves gave the highest $\mathrm{Zn}$ content (45.52 $\mathrm{mg} / \mathrm{kg} \mathrm{DW}$ ) in urban area of (Nasiriyah city) when compared with rural area (farms north of Nasiriyah) city $(8.67 \mathrm{mg} / \mathrm{kg} \mathrm{DW})$. The results showed that Olea leaves was had significantly $(p<0.05)$ in $\mathrm{Zn}$ content compared to Eucalyptus,

Table 1. Zinc content in trees leaves extracts, (mg / kg DW).

\begin{tabular}{cccc}
\hline \multirow{2}{*}{ Plants } & \multicolumn{2}{c}{ Location } & \multirow{2}{*}{ Mean } \\
\cline { 2 - 3 } & Urban area & Rural area & \\
\hline Eucalyptus leaves & $25.78 \pm 0.37$ & $19.49 \pm 0.46$ & 22.64 \\
Olea leaves & $45.52 \pm 0.25$ & $12.97 \pm 0.24$ & 29.16 \\
Zizphus leaves & $10.57 \pm 0.39$ & $8.67 \pm 0.35$ & 9.62 \\
Conocarpus leaves & $24.45 \pm 0.34$ & $14.41 \pm 0.53$ & 19.43 \\
Mean & 26.58 & 13.84 & \\
\hline
\end{tabular}

L.S.D $=3.20$ 
Zizphus and Conocarpus. Among all trees of Eucalyptus, Conocarpus Zizphus and Conocarpus species showed the highest $\mathrm{Zn}$ content in Eucalyptu followed by Conocarpus and Zizphus respectively. These results indicated that for all plant species and growing environment had influence on $\mathrm{Zn}$ content. Comparing $\mathrm{Zn}$ content from this study and other study data is difficult because of the fact that concentration of Zinc can be influenced by method, extracting solvent, species and growing location (Shrrog et al., 2015; Dayang \& Che, 2013; Azim et al., 2017) reported that zinc content of $24 \mathrm{mg} / \mathrm{kg}$ medicinal plants samples and zinc values ranged from 17.70 to $87.55 \mathrm{mg} / \mathrm{kg}$.

\subsection{The Copper Content of Eucalyptus, Olea, Zizphus and Conocarpus Leaves}

The copper content for four different species of trees (Eucalyptus, Olea, Zizphus and Conocarpus) at two areas of urban and rural is presented in Table 2. For trees leaves the maximum $\mathrm{Cu}$ content were obtained for Eucalyptu and Olea leaves 25.72 to $21.70 \mathrm{mg} / \mathrm{kg}$ DW respectively. The leaves from Conocarpus contained the lowest $\mathrm{Cu}$ content as compared to all other samples. Significant difference $(p<0.05)$ in $\mathrm{Cu}$ content were found among the different leaves and among the grown locations. Among all grown locations urban and rural area in all trees species showed the lowest $\mathrm{Cu}$ content in Conocarpus and Zizphus leaves from urban and rural area (4.60 and 10.67) $\mathrm{mg} / \mathrm{kg}$ DW (3.59 and 9.69) $\mathrm{mg} / \mathrm{kg}$ DW respectively. The $\mathrm{Cu}$ content obtained from Eucalyptus leaves was higher significantly $(p<0.05)$ than the extract obtained from Olea leaves in both grown location (urban and rural area). Significant differences $(p<0.05)$ in $\mathrm{Cu}$ content were found between the two growing locations. Both Nasiriyah city and farms north of Nasiriyah areas had higher $\mathrm{Cu}$ content. When comparing the data from this research with other study, results from different sources seriously differ. The $\mathrm{Cu}$ mean value in this research showed that leaves were higher than that of fruits (Dayang \& Che, 2013; Shrrog et al., 2015; Ayden et al., 2018).

\subsection{The Lead Content of Eucalyptus, Olea, Zizphus and Conocarpus Leaves}

Lead content (expressed as mg/kg dw) in Eucalyptus, Olea, Zizphus and Conocarpus

Table 2. Copper content in trees leaves extracts ( $\mathrm{mg} / \mathrm{kg} \mathrm{DW}$ ).

\begin{tabular}{cccc}
\hline \multirow{2}{*}{ Plants } & \multicolumn{2}{c}{ Location } & \multirow{2}{*}{ Mean } \\
\cline { 2 - 3 } & Urban area & Rural area & \\
\hline Eucalyptus leaves & $25.72 \pm 0.33$ & $12.67 \pm 0.34$ & 19.20 \\
Olea leaves & $21.70 \pm 0.62$ & $14.76 \pm 0.48$ & 20.73 \\
Zizphus leaves & $10.67 \pm 0.38$ & $6.69 \pm 1.13$ & 8.18 \\
Conocarpus leaves & $4.60 \pm 0.50$ & $3.59 \pm 0.56$ & 4.09 \\
Mean & 15.67 & 9.42 & \\
\hline
\end{tabular}

L.S.D $=1.53$ 
Table 3. Lead content in trees leaves extracts (mg/kg DW).

\begin{tabular}{cccc}
\hline \multirow{2}{*}{ Plants } & \multicolumn{2}{c}{ Location } & \multirow{2}{*}{ Mean } \\
\cline { 2 - 3 } & Urban area & Rural area & 0.132 \\
\hline Eucalyptus leaves & $0.194 \pm 0.002$ & $0.052 \pm 0.005$ & 0.075 \\
Olea leaves & $0.136 \pm 0.003$ & $0.015 \pm 0.003$ & 0.093 \\
Zizphus leaves & $0.155 \pm 0.005$ & $0.032 \pm 0.005$ & 0.130 \\
Conocarpus leaves & $0.197 \pm 0.001$ & $0.064 \pm 0.000$ & \\
Mean & 0.173 & 0.040 & \\
\hline
\end{tabular}

L.S.D $=0.019$.

leaves is presented in Table 3. A significant amount of lead was found in Conocarpus leaves and Eucalyptus leaves. Whereas the content of $\mathrm{Pb}$ in Olea leaves to be lower in rural area than in urban area. For urban and rural area, the maximum $\mathrm{Pb}$ were obtained for Conocarpus and Eucalyptus leaves (0.197 and 0.194 $\mathrm{mg} / \mathrm{kg}$ DW) in Nasiriyah city respectively. Between within grown location, urban area showed the higher $(\mathrm{Pb})$ then rural area. Table 3 showed significant difference $(p<0.05)$ in the $\mathrm{Pb}$ content of Eucalyptus, Olea, Zizphus and Conocarpus between urban and rural Conocarpus and Eucalyptus leave for Nasiriyah city gave the highest lead content when compared with farms north of Nasiriyah areas. Low content of $\mathrm{Pb}(0.015 \mathrm{mg} / \mathrm{kg} \mathrm{DW})$ were obtained from Olea leaves in rural area. After Olea leaves, leaves of Zizphus $(0.032 \mathrm{mg} / \mathrm{kg}$ $\mathrm{DW}$ ) had low content of $\mathrm{Pb}$ in extract. One possible reason for the increased $\mathrm{Pb}$ content with the urban areas might be due to the increase in organic matter and topography of the land. $\mathrm{Pb}$ content for the Eucalyptus, Olea, Zizphus and Conocarpus leaves $t$ in this study were lower than that of (Dayang \& Che, 2013; Livia et al., 2015; Taghred et al., 2017) for different plants. The Pb concentration in this research showed that leaves were lower than that of Kamaruzzaman et al. (2009).

\section{Conclusion}

Concentration of heavy metals in trees planted in urban areas is related to the location in the city. Plants near sources of pollution such as main roads increase the accumulation of heavy elements by about twice as much as those of remote areas from sources of pollution. The results indicated that all plants and growing location had influence on heavy metals concentration. Eucalyptu and Olea leaves gave the highest, $\mathrm{Zn}$ and $\mathrm{Cu}$ content in urban area when compared with rural area, so these trees (Eucalyptu and Olea) can be used to treat pollution in cities.

\section{Acknowledgements}

This research was supported by University of Thi-Qar, Faculty of Education for Pure Science, Department of Biology, Iraq. 


\section{Conflicts of Interest}

The author declares no conflicts of interest regarding the publication of this paper.

\section{References}

Abdelhafez, A. A., Abbas, M. H. H., \& Attia, T. M. S. (2014). Environmental Monitoring of Heavy-Metals Status and Human Health Risk Assessment in the Soil of Sahl El-Hessania Area, Egypt. Polish Journal of Environmental Studies, 24, 459-467.

Aksoy, A., Osma, E., \& Leblebici, Z. (2012). Spreading Pellitory (Parietaria judaica L.): A Possible Biomonitor of Heavy Metal Pollution. Pakistan Journal of Botany, 44, 123-127.

Antisari, L. V., Orsini, F., Marchetti, L., Vianello, G., \& Gianquinto, G. (2015). Heavy Metal Accumulation in Vegetables Grown in Urban Gardens. Agronomy for Sustainable Development, Springer Verlag/EDP Sciences/INRA, 35, 1139-1147. https://doi.org/10.1007/s13593-015-0308-Z

AOAC (1984). Official Method of Analysis (14th ed.). Arlington, VA: Association of Official Analytical Chemist.

Bryman, A., \& Cramer, D. (2012). Quantitative Data Analysis with IBM SPSS 23: A Guide for Social Scientists. Abingdon-on-Thames: Routledge. https://doi.org/10.4324/9780203180990

Cetin, M. (2016). Determination of Bioclimatic Comfort Areas in Landscape Planning: A Case Study of Cide Coastline. Turkish Journal of Agriculture-Food Science and Technology, 9, 800. https://doi.org/10.24925/turjaf.v4i9.800-804.872

Dayang, S., \& Che Fauziah, I. (2013). Soil Factors Influencing Heavy Metal Concentrations in Medicinal Plants. Pertanika Journal of Tropical Agricultural Science, 36, 161-177.

Hawkes, J. S. (1997). Heavy Metals. Journal of Chemical Education, 74, 1374. https://doi.org/10.1021/ed074p1374

Huseyinova, R., Kutbay, H. G., Bilgin, A., Kılıc, D., Horuz, A., \& Kirmanoğlu, C. (2009). Sulphur and Some Heavy Metals Content in Foliage of Corylus avellana and Some Road Side Native Plants in Ordu Province. Turkey. Ekoloji, 70, 10-16.

https://doi.org/10.5053/ekoloji.2009.702

Hutton, M., \& Symon, C. (1986). The Quantities of Cadmium, Lead, Mercury and Arsenic Entering the UK Environment from Human Activities. Science of the Total Environment, 57, 129-150. https://doi.org/10.1016/0048-9697(86)90018-5

Jansen, E., Michels, M., \& Van Til, M. P. (1994). Effects of Heavy Metals in Soil on Microbial Diversity and Activity as Shown by the Sensitivity-Resistance Index, an Ecologically Relevant Parameter. Biology and Fertility of Soils, 17, 177-184. https://doi.org/10.1007/BF00336319

Kamaruzzaman, B., Ong, M. C., Jalal, K., Shahbudin, S., \& Nor, O. M. (2009). Accumulation of Lead and Copper in Rhizophora apiculata from Setiu Mangrove Forest, Terengganu, Malaysia.

Kulshreshtha, S., Mathur, N., \& Bhatnagar, P. (2010). Bioremediation of Industrial Waste through Mushroom Cultivation. Journal of Environmental Biology, 31, 441-444.

Lone, M. I., He, Z., Stoffella, P. J., \& Yang, X. (2008). Phytoremediation of Heavy Metal Polluted Soils and Water: Progresses and Perspectives. Journal of Zhejiang University SCIENCE, 3, 210-220. https://doi.org/10.1631/jzus.B0710633

Malakootian, M., Aboli, M., \& Ehrampoosh, M. (2009). Determination of Lead Level in 
Lettuce in Kerman. Tolooe Behdasht, 8, 62-67.

Miller, Jr., G. T. (2007). Living in the Environment: Principles, Connections, and Solutions (15th Ed.). Belmont, CA: Thomson Brook/Cole.

Monni, S., Salemaa, M., White, C., Tuittila, E., \& Huopalainen, M. (2000). Copper Resistance of Calluna vulgaris Originating from the Pollution Gradient of a Cu-Ni Smelter in Southwest Finland. Environmental Pollution, 109, 211-219. https://doi.org/10.1016/s0269-7491(99)00265-1

Ozturk, A., Yarci, C., \& Ozyigit, I. I. (2017). Assessment of Heavy Metal Pollution in Istanbul Using Plant (Celtisaustralis L.) and Soil Assays. Biotechnology \& Biotechnological Equipment, 31, 948-954. https://doi.org/10.1080/13102818.2017.1353922

Shrrog, H. H., Wan Juliana, W. A., \& Aminah, A. (2015). Content of Heavy Metals in Plant and Soil Collected from Urban and Remote Natural Habitats. World Applied Sciences Journal, 8, 1373-1379.

Taghred, A., Hashim, H. H., Abbas, I. M., Farid, O. H., El-Husseiny, M., \& Abbas, M. H. H. (2017). Accumulation of Some Heavy Metals in Plants and Soils Adjacent to Cairo-Alexandria Agricultural Highway. Egyptian Journal of Soil Science, 2, 215-232. https://doi.org/10.21608/ejss.2016.281.1047

Turkyilmaz, A., Sevik, H., Cetin, M., \& Ahmaida Saleh, E. A. (2018). Changes in Heavy Metal Accumulation Depending on Traffic Density in Some Landscape Plants. Polish Journal of Environmental Studies, 27, 2277-2284. https://doi.org/10.15244/pjoes/78620 